\title{
Meta-analysis of individual patient data in randomised trials of self monitoring of blood glucose in people with non-insulin treated type 2 diabetes
}

\author{
Andrew J Farmer professor of general practice ${ }^{1}$, Rafael Perera university lecturer ${ }^{1}$, Alison Ward \\ director of postgraduate studies ${ }^{1}$, Carl Heneghan reader ${ }^{1}$, Jason Oke medical statistician ${ }^{1}$, Anthony \\ $\mathrm{H}$ Barnett professor of medicine ${ }^{2}$, Mayer B Davidson professor of medicine ${ }^{3}$, Bruno Guerci professor \\ of medicine ${ }^{4}$, Vivien Coates professor of nursing research ${ }^{5}$, Ulrich Schwedes diabetologist ${ }^{6}$, Simon \\ O'Malley registrar in general practice ${ }^{7}$
}

${ }^{1}$ Department of Primary Health Care, University of Oxford, and NIHR School for Primary Care Research, Oxford OX1 2ET, UK; ${ }^{2}$ Division of Clinical and Experimental Medicine, University of Birmingham and BioMedical Research Centre, Heart of England NHS Foundation Trust, UK; ${ }^{3}$ Department of Internal Medicine, Charles Drew University, Los Angeles, CA, USA; ${ }^{4}$ Diabetologie, Maladies Metaboliques \& Nutrition, Hôpital Brabois, CHU de Nancy, et CIC Inserm, Vandoeuvre-lès-Nancy, France; ${ }^{5}$ Institute for Nursing Research, University of Ulster, Coleraine, Northern Ireland, UK; ${ }^{6}$ Diabetes Zentrum Hamburg City, Hamburg, Germany; ${ }^{7}$ Royal Berkshire NHS Foundation Trust, Reading, UK

\begin{abstract}
Objective To assess the effectiveness of self monitoring blood glucose levels in people with non-insulin treated type 2 diabetes compared with clinical management without self monitoring, and to explore the effects in specific patient groups.

Design Meta-analysis based on individual participant data.

Data sources Medline, Embase, and a recent systematic review of trials on self monitoring of blood glucose. Chief investigators of trials published since 2000 were approached for additional information and individual patient data.

Inclusion criteria Randomised controlled trials in patients with non-insulin treated type 2 diabetes comparing an intervention using self monitoring of blood glucose with clinical management not using self monitoring. Trials published from 2000 with at least 80 participants were included.
\end{abstract}

Data collection Individual patient data were collected from electronic files and checked for integrity.

Analysis All randomised participants were analysed using the intention to treat principle. A random effects model of complete cases was used to assess efficacy, a sensitivity analysis comprised imputed data, and prespecified subgroup analyses were carried out for age, sex, previous use of self monitoring, duration of diabetes, and levels of glycated haemoglobin $\left(\mathrm{HbA}_{1 \mathrm{c}}\right)$ at baseline.
Results 2552 patients were randomised in the six included trials. A mean reduction in $\mathrm{HbA}_{1 \mathrm{c}}$ level of $-2.7 \mathrm{mmol} / \mathrm{mol}$ (95\% confidence interval -3.9 to $-1.6 ; 0.25 \%$ ) was observed for those using self monitoring of blood glucose levels compared with no self monitoring at six months. The mean reduction in $\mathrm{HbA}_{1 \mathrm{c}}$ level between groups was $2.0 \mathrm{mmol} / \mathrm{mol}$ (3.2 to $0.8 ; 0.25 \%$ ) at three months (five trials) and $2.5 \mathrm{mmol} / \mathrm{mol}(4.1$ to $0.9 ; 0.35 \%$ ) at 12 months (three trials). These estimates were unchanged after imputing missing data, and estimates of effect in trials with higher loss to follow-up or a possibility of co-intervention compared with those with lower loss to follow-up and no co-intervention did not differ significantly $(P=0.21)$. The difference in $\mathrm{HbA}_{1 \mathrm{c}}$ levels between groups was consistent across age, baseline $\mathrm{HbA}_{1 \mathrm{c}}$ level, sex, and duration of diabetes, although the numbers of older and younger people and those with $\mathrm{HbA}_{1 \mathrm{c}}$ levels $>86 \mathrm{mmol} / \mathrm{mol}(10 \%)$ were insufficient for interpretation. No changes occurred in systolic blood pressure $(-0.2 \mathrm{~mm}$ $\mathrm{Hg}, 95 \%$ confidence interval -1.4 to 1.0$)$, diastolic blood pressure $(-0.1$ $\mathrm{mm} \mathrm{Hg},-0.9$ to 0.6$)$, or total cholesterol level $(-0.1 \mathrm{~mol} / \mathrm{L}, 95 \%$ confidence interval -0.2 to 0.1 ).

Conclusions Evidence from this meta-analysis of individual patient data was not convincing for a clinically meaningful effect of clinical management of non-insulin treated type 2 diabetes by self monitoring of blood glucose levels compared with management without self monitoring, although the difference in $\mathrm{HbA}_{1 \mathrm{c}}$ level between groups was 
statistically significant. The difference in levels was consistent across subgroups defined by personal and clinical characteristics.

\section{Introduction}

Self monitoring of blood glucose is generally accepted as integral to the management of diabetes, particularly for people who require insulin. ${ }^{1}$ Typically, a meter device measures blood glucose levels in a fingertip sample of capillary blood and the data are used by patients and clinicians to determine the presence of hyperglycaemia or hypoglycaemia and to inform decisions about adjustment of insulin dosage, use of other drugs, or aspects of lifestyle that may need to be changed, such as meals and physical activity. Evidence on the effectiveness of self monitoring blood glucose in people with non-insulin treated type 2 diabetes is less clear cut however. ${ }^{2}$ In a series of systematic reviews and meta-analyses, estimates for the effect of self monitoring blood glucose varied. ${ }^{3-6}$ Whether these findings were accounted for by differences in trial designs, recruited populations, or the methods used to pool the data are uncertain. It is also unclear whether particular groups of people may benefit more than others from a period of self monitoring. We pooled the data from a series of randomised controlled trials of self monitoring of blood glucose in people with non-insulin treated type 2 diabetes, excluding trials with a small sample size and limited follow-up. ${ }^{7} \mathrm{We}$ also evaluated more recent trials examining the use of blood glucose measuring devices that incorporated electrochemical sensors and technology to minimise inaccurate measurements.

\section{Methods}

We searched the bibliography of a recent high quality systematic review to identify trials that evaluated self monitoring of blood glucose levels in people with non-insulin treated type 2 diabetes reported between January 2000 and April 2009. ${ }^{3}$ We searched Medline and Embase from April 2009 to June 2010 with the same search terms as used in the review (see web extra on bmj.com). To identify further trials we also hand searched other systematic reviews of glucose self monitoring, conference proceedings and abstracts, and the current controlled trials register. No language restrictions were applied.

\section{Selection criteria and validity assessment}

We selected randomised controlled clinical trials comparing an intervention of self monitoring of blood glucose in people with non-insulin treated type 2 diabetes with clinical management not using self monitoring and that assessed glycaemic control by using $\mathrm{HbA}_{\mathrm{cc}}$ as a primary outcome. Secondary outcomes included blood pressure and serum cholesterol level. Trials were required to include an active intervention arm intended to improve disease outcomes through incorporating self monitoring into self management, and a comparator arm not using self monitoring and with no additional modification of risk factors or behaviour intended.

We determined the methodological quality of selected trials by assessing randomisation, allocation concealment, blinded outcome assessment, losses to follow-up, funding source, and follow-up rates. ${ }^{8}$ Two additional quality criteria were also included: a minimum sample size of 80 patients and a minimum study duration of six months.

\section{Specification of intervention and comparator groups}

From published reports we obtained the details of the trial designs, interventions, comparator groups, and conduct, which we then verified with the trialists. The details included use of concealed allocation, dropout rates, the intended frequency of self monitoring, training in the self management intervention, frequency and timing of self monitoring measurements, and delivery of co-interventions. To identify the extent to which educational interventions were matched with the intervention we examined the comparator groups. We also collected details of any factors used to stratify the sample.

\section{Extraction of individual patient data}

We contacted the principal investigators for the original individual patient data. The following baseline data, where available, were provided: date of randomisation, age, sex, ethnicity, smoking status, duration of diabetes, glucose lowering treatment, previous use of blood glucose testing, weight, height, blood pressure, and levels of total cholesterol, plasma glucose, and $\mathrm{HbA}_{1 \mathrm{c}}$. In addition the allocated treatment, methods of $\mathrm{HbA}_{1 \mathrm{c}}$ analysis, and trial outcomes were provided, including $\mathrm{HbA}_{1 \mathrm{c}}$ level, blood pressure, and serum cholesterol level. All randomised patients with a database record were entered in the pooled database. We retrieved patients lost to follow-up or excluded in published per protocol analyses and included them in the database of individual patient data.

\section{Quantitative data synthesis}

The protocol for the study has been published ${ }^{9}$ and a statistical plan was agreed before starting data analysis. Codes for treatment allocation were not provided until the end of the analysis process. The main analysis, including primary, secondary, and other exploratory analyses, was based on intention to treat, in which we considered all randomised participants. Where a trial included two intervention arms, we pooled these to obtain a single intervention group for the analysis. ${ }^{8}$ We report analyses for $\mathrm{HbA}_{1 \mathrm{c}}$ at 3, 6, and 12 months after the intervention. If $\mathrm{HbA}_{1 \mathrm{c}}$ outcome data were available at two and four months, we averaged the figures to provide an estimate of the outcome at three months.

Analyses were undertaken to estimate treatment effects by fitting a two level regression model, with patients corresponding to level one units and trials as level two. ${ }^{10}$ We treated trial specific differences as random effects and assumed the treatment effect to be common across trials. All analyses were adjusted for baseline measures and where missing were imputed using the missing indicator method. ${ }^{11}$ To assess potential confounding we further adjusted analyses for age, sex, and duration of diabetes. We present the results for all analyses with appropriate measures of effect, 95\% confidence intervals, and $\mathrm{P}$ values where applicable.

For those trials where relevant data were not available we investigated the potential for bias-in particular, in trials with high levels of attrition. We handled missing primary outcomes in the regression models by adopting a bayesian approach, ${ }^{12}$ which imputes the outcome variable directly from the model, and we used these estimates as part of extended sensitivity analyses. Additional sensitivity analyses were carried out for trials with higher rates of loss to follow-up or with potential for an additional impact from a co-intervention with the use of self monitoring. Analyses were carried out using R version 2.13 (R Foundation for Statistical Computing, Vienna) and Stata version 11.1 . 


\section{Results}

Of the 272 studies retrieved from the database search, and the additional studies from the bibliography of the high quality systematic review, ${ }^{3} 15$ trials were identified. Of these, three included self monitoring in both trial arms, ${ }^{13-15}$ one included multiple co-interventions alongside self monitoring that were not available to the comparator group,${ }^{16}$ three included patients treated with insulin, ${ }^{17-19}$ one was a trial of financial incentives to use self monitoring, ${ }^{20}$ and one included patients with type 1 diabetes. ${ }^{21}$ No trials identified to June 2010 were excluded solely because of inclusion of fewer than 80 patients.

The remaining six trials with 2552 patients met the criteria for inclusion in the analysis, and data were available for each of them. Included trials were carried out in the United States, ${ }^{22}$ France, ${ }^{23}$ Germany, ${ }^{24}$ and the United Kingdom, ${ }^{25}{ }^{26}$ and a sixth trial was a multicentre European trial. ${ }^{27}$

Table $1 \Downarrow$ shows the characteristics of each trial (see web extra table for full details). With the exception of one trial ${ }^{25}$ that recruited newly diagnosed patients, trials recruited participants with established type 2 diabetes not treated with insulin. Interventions varied but focused around management of lifestyle ${ }^{24} 25$ or adjustment of drugs. ${ }^{22}{ }^{27}$ One trial included a continuing dietary intervention for the duration of the trial alongside self monitoring. ${ }^{24}$ One trial included two intervention arms. ${ }^{26}$ Trials varied in size from $89^{22}$ to 689 participants, ${ }^{23}$ in duration from six to 12 months, and in losses to follow-up from $2 \%$ to $31 \%$. ${ }^{23}$ Table $2 \Downarrow$ reports the methods used in each of the trials.

Table $3 \Downarrow$ shows the characteristics of the trial participants. The mean age was 60.1 years (SD 10.2) and body mass index 30.9 (SD 5.9). The median duration of diabetes was 36 months (interquartile range 12-89). Baseline $\mathrm{HbA}_{\mathrm{lc}}$ was $67.0 \mathrm{mmol} / \mathrm{mol}$ (SD 16.0): 8.3\% (SD 1.4\%). There was a slight excess of men $(54 \% v 46 \%)$ and, in those trials providing data, most participants were new to testing.

Figure $1 \Downarrow$ and table $4 \Downarrow$ show glycaemic outcomes for the main complete case comparison of self monitoring with no self monitoring of blood glucose levels. Adjusted $\mathrm{HbA}_{\mathrm{lc}}$ levels at six months were $2.7 \mathrm{mmol} / \mathrm{mol}(0.25 \%)$ significantly lower in the intervention group than in the control group $(\mathrm{P}<0.001)$.

Secondary adjusted glycaemic outcomes at three and 12 months were also significantly lower, at $2.0 \mathrm{mmol} / \mathrm{mol}(0.18 \% ; \mathrm{P}=0.001)$ and $2.5 \mathrm{mmol} / \mathrm{mol}(0.23 \% ; \mathrm{P}=0.002)$. For two trials the $\mathrm{HbA}_{1 \mathrm{c}}$ outcomes at three months included the average of the measurements at two and four months. ${ }^{22}$

Figure $2 \Downarrow$ and table 4 shows the change in $\mathrm{HbA}_{1 \mathrm{c}}$ levels for intervention and control groups over three months for the five trials with data available over this period. $\mathrm{HbA}_{\mathrm{lc}}$ levels decreased from baseline in both groups at three and six months, with a consistent difference evident between the groups at three months. Other outcomes, including systolic and diastolic blood pressure and serum cholesterol level were not significantly different between groups, as confirmed by sensitivity analyses. Blood pressure outcomes were combinations of measurements at six months ${ }^{23}$ and 12 months. ${ }^{26}$ For total cholesterol level the outcome was a combination of outcomes at six months ${ }^{24} 27$ and 12 months. $^{26}$

Figure $3 \Downarrow$ shows the results of the preplanned subgroup analysis. For participants aged 45 to 75 years a consistent effect of self monitoring was evident. Only a few participants were aged less than 45 years and more than 75 years, and the confidence intervals of the estimates for these subgroups were wide. The difference in effect between men and women and between individuals with varied durations of diabetes did not differ. Evidence was also lacking of a differing effect for individuals with varied baseline levels of $\mathrm{HbA}_{1 \mathrm{c}}$, although few data were available for those with an $\mathrm{HbA}_{1 \mathrm{c}}$ level above $10 \%$ (86 $\mathrm{mmol} / \mathrm{mol}$ )

A sensitivity analysis based on imputing data gave similar results to the primary analysis, with a reduction in $\mathrm{HbA}_{1 \mathrm{c}}$ level of 2.7 $\mathrm{mmol} / \mathrm{mol}$ (95\% confidence interval 3.8 to $1.6,0.25 \%$ ) at six months. Evidence of heterogeneity in outcomes was lacking between the trials. Outcomes did not differ significantly $(\mathrm{P}=0.21)$ in an additional sensitivity analysis comparing trials with a greater loss to follow-up and additional dietary intervention with the remainder of the trials.

\section{Discussion}

Our analysis suggests that clinical management of non-insulin treated diabetes using self monitoring of blood glucose levels compared with no self monitoring results in a reduction in $\mathrm{HbA}_{1 \mathrm{c}}$ level of around $2.7 \mathrm{mmol} / \mathrm{mol}(0.25 \%)$. In trials measuring outcomes the reduction in levels at six months was apparent at three months and 12 months. The mean pooled reduction in $\mathrm{HbA}_{\mathrm{lc}}$ levels across the trials was $9.6 \mathrm{mmol} / \mathrm{mol}(0.88 \%)$ in the intervention group and $7.5 \mathrm{mmol} / \mathrm{mol}(0.69 \%)$ in the comparator group. No change in $\mathrm{HbA}_{1 \mathrm{c}}$ level was observed for older and younger people and those with a level above $86 \mathrm{mmol} / \mathrm{mol}$ (10\%), although confidence intervals were wide, but otherwise a consistent effect of a small reduction in $\mathrm{HbA}_{1 \mathrm{c}}$ level was observed in other prespecified subgroups. The numbers of patients included in the analysis were too small to confidently exclude a difference in response between those who had previously used self monitoring compared with those who had not. The differences in the effect size observed between individual trials did not suggest that differences in the way self monitoring has been used to date or the characteristics of trial participants might contribute to important differences in the observed effect.

\section{Strengths and limitations of the review}

This analysis reports, for the first time, the results of pooling individual data from recent trials comparing self monitoring of blood glucose with no self monitoring. The results of the individual trials can be compared by using a common analysis plan, and the impact of self monitoring can now be observed in prespecified subgroups. A statistical analysis plan, written before the data were examined, contributes to the rigour of this analysis. The participants included in this analysis were drawn from a wide range of settings but are representative of people with non-insulin treated type 2 diabetes and therefore the findings can be applied widely. No heterogeneity was observed in outcomes between trials and therefore we have not included further analysis of differences between populations, interventions, and trial design variables. In any case the limited number of trials would not have justified such an exploratory analysis. This collaboration forms the basis of a group that can facilitate continued meta-analysis of self monitoring trials, explore co-interventions designed to enhance the effective use of self monitoring, and investigate the potential for improved outcomes from occasional or intermittent use of self monitoring in addition to regular use.

Despite the insights that can be obtained from an individual patient data analysis, there are several limitations to the interpretation of data. In particular, the interventions used in each trial were intended to reflect best practice as seen at the time of the trial's design, which may not reflect subsequent 
developments in the use of self monitoring in clinical practice. The design of the trials reflects their "real world" settings and the difficulty of identifying the additional impact of self monitoring beyond good clinical care. For simplicity in reporting we used a linear imputation to extrapolate the measurement of $\mathrm{HbA}_{1 \mathrm{c}}$ at three months from these two measures and calculated the difference in levels between the intervention and comparator group. As this is a direct comparison between randomised groups, any difference between this linear approximation and alternative methods of extrapolation is likely to be negligible. The data that could be obtained and pooled across the trials did not extend to markers of safety-for example, incidence of hypoglycaemia, although individual trials did provide data reporting low rates of recorded hypoglycaemia. ${ }^{25}{ }^{26} \mathrm{In}$ addition, data about socioeconomic groupings and changes to treatment were insufficient to explore their impact on the changes in $\mathrm{HbA}_{1 \mathrm{c}}$ levels, cholesterol levels, and blood pressure. Other limitations noted for individual trials included inclusion of people with a blood glucose level potentially too low to benefit from the intervention ${ }^{26}$; interventions in people with newly diagnosed diabetes, with poor control likely to improve without self monitoring ${ }^{25}$ 27 ; high rates of loss to follow-up ${ }^{23}$; and the presence of concerns about the contribution of a dietary co-intervention with self monitoring of glucose to outcomes. ${ }^{24}$

All the trials excluded patients actively using self monitoring blood glucose levels; a recent survey indicated the type of benefits that many have gained from personalised use of the technology, ${ }^{28}$ and that they may be less willing to take part in randomised trials. Our data provide an indication, although not statistically significant, that those who have used self monitoring in the past may benefit less than a group newly exposed to the technology. Self monitoring of blood glucose is not simply a diagnostic tool but one component of a complex intervention aimed at improving overall glycaemic control and wellbeing. The future use of self monitoring depends on integrating the technology in clinical and behavioural management pathways. Poor use of monitoring may mean wasted resources, an important consideration as the market for glucose self monitoring for all types of diabetes approached $\$ 8.8 \mathrm{bn}$ ( $£ 5.6 \mathrm{bn}$; $€ 6.8 \mathrm{bn}$ ) worldwide in $2008,{ }^{29}$ with estimated annual UK costs of $£ 38 \mathrm{~m}$ in type 2 diabetes, ${ }^{30}$ of which up to $£ 34 \mathrm{~m}$ may be attributable to use in non-insulin treated type 2 diabetes. ${ }^{3}$

The pooled estimate of the benefit from using self monitoring from our analysis is in line with most ${ }^{3563132}$ but not all of the analyses carried out that previously used aggregated data. ${ }^{4}$ Our findings do not, however, support previous assertions that the overall reduction in $\mathrm{HbA}_{1 \mathrm{c}}$ level may be greater when treating those with higher compared with lower $\mathrm{HbA}_{1 \mathrm{c}}$ levels. ${ }^{633} 34$ Although intuitively it might seem that greater reductions in $\mathrm{HbA}_{1 \mathrm{c}}$ levels are possible with a higher initial level, similar reductions were also observed in the control groups.

\section{Clinical implications}

It is widely agreed that for further evaluation of self monitoring of blood glucose, the therapeutic interventions and efforts to promote behavioural change should be more tightly aligned to the results obtained from monitoring, and targeted at those likely to benefit. ${ }^{2}$ Early studies linking test results to specific drug and behavioural strategies have had promising results, ${ }^{35} 36$ although not achieving the $0.5 \%$ reduction in $\mathrm{HbA}_{\mathrm{lc}}$ that is generally accepted to be of clinical relevance. ${ }^{3}$ Smaller reductions of $\mathrm{HbA}_{1 \mathrm{c}}$ level might be of importance from a public health perspective if achieved on a wide scale and at lower cost; however, costs of self monitoring remain high, even in low and middle income countries, with the costs of unsubsidised test strips varying from $\$ 0.35$ in Australia to $\$ 3.11$ in India. ${ }^{37}$ Until further studies can establish potential target groups and promising interventions to improve glycaemic control with self monitoring, our meta-analysis using individual patient data does not provide convincing evidence to support its routine use for people with non-insulin treated type 2 diabetes using the range of interventions employed within the included trials.

We thank Alice Fuller for collating the data and Julie McLellan for her help with identifying eligible trials.

Contributors: AJF and RP designed the study. AJF, AHB, MBD, BG, VC, and US contributed data. $\mathrm{AW}$ and $\mathrm{CH}$ collated the data. AJF and RP wrote the statistical analysis plan. JO and RP carried out the analysis. All authors reviewed the data. AJF wrote the draft of the paper and all authors commented on the draft. The funding source had no input into the study design, data collection, analysis, interpretation of the data, report preparation, or in the decision to submit the paper for publication. The corresponding author had full access to all the data in the study and had final responsibility for the decision to submit for publication

Funding: AJF, RP, AW, JO, and $\mathrm{CH}$ are members of the National Institute for Health Research (NIHR) School of Primary Care. AJF receives support from the NIHR Oxford Biomedical Research Centre.

Competing interests: All authors have completed the ICMJE uniform disclosure form at www.icmje.org/coi_disclosure.pdf (available on request from the corresponding author) and declare: this work is supported by the NIHR Health Technology Assessment Programme (grant No 018/0004); AHB has received lecture fees and advisory payments from LifeScan Scotland and Roche; no other relationships or activities are reported that could appear to have influenced the submitted work. The opinions expressed in this paper are not necessarily those of the Department of Health, UK.

Ethical approval: Not required.

Data sharing: No additional data available.

Naik RG, Ellis SL. Self-monitoring of blood glucose in insulin-requiring type 2 diabetes. Diabetes Technol Ther 2008;10(suppl 1):S67-71.

2 International Diabetes Federation. Self-monitoring of blood glucose in non-insulin-treated type 2 diabetes. IDF Publications, 2009.

3 Clar C, Barnard K, Cummins E, Royle P, Waugh N. Self-monitoring of blood glucose in type 2 diabetes: systematic review. Health Technol Assess 2010;14:1-140.

4 Sarol JN Jr, Nicodemus NA Jr, Tan KM, Grava MB. Self-monitoring of blood glucose as part of a multi-component therapy among non-insulin requiring type 2 diabetes patients: a meta-analysis (1966-2004). Curr Med Res Opin 2005;21:173-84.

5 Towfigh A, Romanova M, Weinreb JE, Munjas B, Suttorp MJ, Zhou A, et al. Self-monitoring of blood glucose levels in patients with type 2 diabetes mellitus not taking insulin: a meta-analysis. Am J Manag Care 2008:14:468-75.

6 Poolsup N, Suksomboon N, Rattanasookchit S. Meta-analysis of the benefits of self-monitoring of blood glucose on glycemic control in type 2 diabetes patients: an update. Diabetes Technol Ther 2009;11:775-84.

7 Piantadosi S. MetaAnalysis. Clinical trials: a methodological perspective. 2nd ed. Wiley, 2005.

8 Higgins JP, Green S. Cochrane handbook for systematic reviews of interventions. Wiley, 2008.

9 Farmer AJ, Heneghan C, Barnett AH, Davidson MB, Guerci B, O'Kane M, et al. Individual patient data meta-analysis of trials of self-monitoring of blood glucose in non-insulin treated type 2 diabetes: protocol for a systematic review. Primary Care Diabetes 2009;3:117-21

10 Simmonds MC, Higgins JP, Stewart LA, Tierney JF, Clarke MJ, Thompson SG. Meta-analysis of individual patient data from randomized trials: a review of methods used in practice. Clin Trials 2005;2:209-17.

11 White IR, Thompson SG. Adjusting for partially missing baseline measurements in randomized trials. Stat Med 2005;24:993-1007.

12 Gelman A, Hill J. Data analysis using regression and multilevel/hierarchical models. Cambridge University Press, 2007.

13 Joy S, Rodgers $\mathrm{P}$. Elmore L, Calvert S. Assessment of therapeutic interventions and degree of glycemic control for patients with type 2 diabetes mellitus using preprandial versus postprandial self blood glucose monitoring in a primary care setting. Diabetes 2003;52:A96-7.

14 Bonomo K, De Salve A, Fiora E, Mularoni E, Mussucco P, Poy P, et al. Evaluation of a simple policy for pre- and post-prandial blood glucose self-monitoring in people with type 2 diabetes not on insulin. Diabetes Res Clin Prac 2010;87:246-51.

15 Scherbaum WA, Ohmann C, Abholz HH, Dragano N, Lankisch M. Effect of the frequency of self-monitoring blood glucose in patients with type 2 diabetes treated with oral antidiabetic drugs_-a multi-centre, randomized controlled trial. PLoS One 2008;28;3:e3087.

16 Brown SA, Garcia AA, Kouzekanani K, Hanis CL. Culturally competent diabetes self-management education for Mexican Americans: the Starr County border health initiative. Diabetes Care 2002;25:259-68. 


\section{What is already known on this topic}

Self monitoring of blood glucose level is essential for the management of type 1 diabetes and insulin treated type 2 diabetes

The use of self monitoring for non-insulin treated people has been controversial because estimates of benefit in reducing levels of $\mathrm{HbA}_{1}$

vary between systematic reviews

No single trial has been large enough to identify the characteristics of those who might benefit most from monitoring blood glucose

\section{What this study adds}

Meta-analysis using individual patient data lacked convincing evidence to support the routine use of self monitoring of blood glucose in people with non-insulin treated type 2 diabetes

Evidence was also lacking of a greater effect from self monitoring in patients with a baseline $\mathrm{HbA}_{1 \mathrm{c}}$ level above $8 \%$

Better evidence that self monitoring can provide feedback on treatment and behaviour are needed before further large scale trials are carried out

17 Cho JH, Chang SA, Kwon HS, Choi YH, Ko SH, Moon SD, et al. Long-term effect of the Internet-based glucose monitoring system on $\mathrm{HbA} 1 \mathrm{c}$ reduction and glucose stability: a 30-month follow-up study for diabetes management with a ubiquitous medical care system. Diabetes Care 2006;29:2625-31.

18 Kwon HS, Cho JH, Kim HS, Song BR, Ko SH, Lee JM, et al. Establishment of blood glucose monitoring system using the internet. Diabetes Care 2004;27:478-83.

19 Moreland EC, Volkening LK, Lawlor MT, Chalmers KA, Anderson BJ, Laffel LMB. Use of a blood glucose monitoring manual to enhance monitoring adherence in adults with diabetes: a randomized controlled trial. Arch Intern Med 2006;166:689-95.

20 Johnson JA, Majumdar SR, Bowker SL, Toth EL, Edwards A. Self-monitoring in type 2 diabetes: a randomized trial of reimbursement policy. Diabet Med 2006;23:1247-51.

21 Jones H, Edwards L, Vallis TM, Ruggiero L, Rossi SR, Rossi JS, et al. Changes in diabetes self-care behaviors make a difference in glycemic control: the Diabetes Stages of Change (DiSC) Study. Diabetes Care 2003:26:732-7.

22 Davidson MB, Castellanos M, Kain D, Duran P. The effect of self monitoring of blood glucose concentrations on glycated hemoglobin levels in diabetic patients not taking insulin: a blinded, randomized trial. Am J Med 2005;118:422-5.

23 Guerci B, Drouin P, Grange V, Bougneres P, Fontaine P, Kerlan V, et al. Self-monitoring of blood glucose significantly improves metabolic control in patients with type 2 diabetes mellitus: the Auto-Surveillance Intervention Active (ASIA) Study. Diabetes Metab 2003:29:587-94.

24 Schwedes U, Siebolds M, Mertes G. Meal-related structured self-monitoring of blood glucose: effect on diabetes control in non-insulin-treated type 2 diabetic patients. Diabetes Care 2002;25:1928-32.

25 O'Kane MJ, Bunting B, Copeland M, Coates VE, on behalf of the ESMON study group. Efficacy of self monitoring of blood glucose in patients with newly diagnosed type 2 diabetes (ESMON study): randomised controlled trial. BMJ 2008;336:1174-7.

26 Farmer A, Wade A, Goyder E, Yudkin P, French D, Craven A, et al. Impact of self monitoring of blood glucose in the management of patients with non-insulin treated diabetes: open parallel group randomised trial. BMJ 2007;335:132.

27 Barnett AH, Krentz AJ, Strojek K, Sieradzki J, Azizi F, Embong M, et al. The efficacy of self-monitoring of blood glucose in the management of patients with type 2 diabetes treated with a gliclazide modified release-based regimen. A multicentre, randomized, parallel-group, 6-month evaluation (DINAMIC 1 study). Diabet Obes Metab 2008; 10:1239-47.

28 Barnard KD, Young AJ, Waugh NR. Self monitoring of blood glucose-a survey of diabetes UK members with type 2 diabetes who use SMBG. BMC Res Notes 2010;3:318.
29 Hughes MD. The business of self-monitoring of blood glucose: a market profile. J Diabetes Sci Technol 2009;3:1219-23.

30 Belsey JD, Pittard JB, Rao S, Urdahl H, Jameson K, Dixon T. Self blood glucose monitoring in type 2 diabetes. A financial impact analysis based on UK primary care. Int J Clin Pract 2009;63:439-48.

31 St John A, Davis WA, Price CP, Davis TM. The value of self-monitoring of blood glucose: a review of recent evidence. J Diabetes Complications 2010;24:129-41.

32 McAndrew L, Schneider SH, Burns E, Leventhal H. Does patient blood glucose monitoring improve diabetes control? A systematic review of the literature. Diabetes Educ 2007;33:991-1010

33 McGeoch G, Derry S, Moore RA. Self-monitoring of blood glucose in type-2 diabetes: what is the evidence? Diabetes Metab Res Rev 2007;23:423-40.

34 Jansen JP. Self-monitoring of glucose in type 2 diabetes mellitus: a Bayesian meta-analysis of direct and indirect comparisons. Curr Med Res Opin 2006;22:671-81.

35 Parkin CG, Hinnen D, Campbell RK, Geil P, Tetrick DL, Polonsky WH. Effective use of paired testing in type 2 diabetes: practical applications in clinical practice. Diabetes Educ 2009;35:915-27.

36 Polonsky WH, Fisher L, Schikman CH, Hinnen DA, Parkin CG, Jelsovsky Z, et al. Structured self-monitoring of blood glucose significantly reduces $\mathrm{A} 1 \mathrm{C}$ levels in poorly controlled, noninsulin-treated type 2 diabetes: results from the Structured Testing Program Study. Diabetes Care 2011;34:262-7.

37 Bot S, Davis TME, Davis WA, Farmer A, Gagliardino JJ, Giorda C, et al. Self-monitoring of blood glucose in type 2 diabetes: an inter-country comparison. Diabetes Res Clin Pract 2008;82:e15-8.

Accepted: 14 November 2011

\section{Cite this as: BMJ 2012;344:e486}

This is an open-access article distributed under the terms of the Creative Commons Attribution Non-commercial License, which permits use, distribution, and reproduction in any medium, provided the original work is properly cited, the use is non commercial and is otherwise in compliance with the license. See: $\mathrm{http}: / /$ creativecommons.org/licenses/bync/2.0/ and http://creativecommons.org/licenses/by-nc/2.0/legalcode. 


\section{Tables}

\begin{tabular}{|c|c|c|c|c|c|c|}
\hline Studies & Summary of trial & $\begin{array}{l}\text { Duration of } \\
\text { intervention }\end{array}$ & Setting & $\begin{array}{c}\text { No of } \\
\text { participants }\end{array}$ & $\begin{array}{l}\text { No of visits for } \\
\text { each participant }\end{array}$ & Timing of visits \\
\hline $\begin{array}{l}\text { Barnett et al } \\
2008^{27}\end{array}$ & $\begin{array}{l}\text { Multicentre, randomised parallel group trial } \\
\text { comparing self monitoring of blood glucose } \\
\text { and non-self monitoring of blood glucose } \\
\text { groups in gliclazide based regimen }\end{array}$ & 27 weeks & Specialist centres & 519 & 7 visits & $\begin{array}{l}\text { At weeks }-2,0,3,6,9 \\
18 \text {, and } 27\end{array}$ \\
\hline $\begin{array}{l}\text { Davidson et al } \\
2005^{22}\end{array}$ & $\begin{array}{l}\text { Blinded, }{ }^{*} \text { randomised trial comparing } \\
\text { monitoring group with control group with } \\
\text { nurse provider making clinical management } \\
\text { decisions }\end{array}$ & 6 months & Community clinic & 89 & $\begin{array}{l}5 \text { with dietitian, } \\
\text { number with nurse } \\
\text { not specified }\end{array}$ & $\begin{array}{l}\text { At weeks } 0,2,4,8 \text {, and } \\
12 \text { with dietitian, those } \\
\text { with nurse not specified }\end{array}$ \\
\hline $\begin{array}{l}\text { Farmer 2007et } \\
\mathrm{al}^{26}\end{array}$ & $\begin{array}{l}\text { Three arm, open parallel group randomised } \\
\text { trial testing whether self monitoring of blood } \\
\text { glucose, with or without instruction in } \\
\text { incorporating findings into self care, } \\
\text { compared with usual care can improve } \\
\text { glycaemic control in people with non-insulin } \\
\text { treated diabetes }\end{array}$ & 12 months & $\begin{array}{l}\text { Patients recruited } \\
\text { from general practice, } \\
\text { not clear where clinic } \\
\text { visits and education } \\
\text { happen }\end{array}$ & 453 & $\begin{array}{l}7 \text { visits and a } \\
\text { telephone call at } 2 \\
\text { weeks }\end{array}$ & $\begin{array}{l}\text { Assessment visit } 2 \\
\text { weeks before } \\
\text { randomisation at week } 0 \text {, } \\
\text { clinic visits at weeks } 4 \text {, } \\
13,26,39 \text {, and } 52\end{array}$ \\
\hline $\begin{array}{l}\text { Guerci et al } \\
2003^{23}\end{array}$ & $\begin{array}{l}\text { An open randomised prospective study } \\
\text { comparing changes in metabolic control in } \\
\text { people managed with usual } \\
\text { recommendations alone or combined with } \\
\text { self monitoring of blood glucose }\end{array}$ & 6 months & General practice & 689 & 5 visits & $\begin{array}{l}\text { At weeks } 0,6,12,18 \text {, } \\
\text { and } 24\end{array}$ \\
\hline $\begin{array}{l}\text { O'Kane et al } \\
2008^{25}\end{array}$ & $\begin{array}{l}\text { Prospective randomised controlled trial of } \\
\text { self monitoring versus no monitoring }\end{array}$ & 1 year & $\begin{array}{l}\text { Outpatient diabetes } \\
\text { services }\end{array}$ & 184 & 5 visits & $\begin{array}{l}\text { At months } 0,3,6,9 \text {, and } \\
12\end{array}$ \\
\hline $\begin{array}{l}\text { Schwedes et al } \\
2002^{24}\end{array}$ & $\begin{array}{l}\text { Prospective, multicentre, randomised } \\
\text { controlled comparing self monitoring of } \\
\text { blood glucose and standardised counselling } \\
\text { with non-standardised counselling }\end{array}$ & $\begin{array}{l}6 \text { months (and } 6 \\
\text { month follow-up) }\end{array}$ & $\begin{array}{l}\text { Outpatients-hospital } \\
\text { and family } \\
\text { practitioners }\end{array}$ & 223 & 5 visits & $\begin{array}{l}\text { At weeks }-2,0,4,12 \text {, } \\
\text { and } 20\end{array}$ \\
\hline
\end{tabular}

See web extra on bmj.com for more detailed table.

*Treatment decisions were made by nurse based on laboratory fasting plasma glucose and $\mathrm{HbA}_{1 \mathrm{c}}$ levels using standard protocol, but did not know which people were self monitoring blood glucose levels. 
Table 2| Assessment of methodological quality of included trials

\begin{tabular}{|c|c|c|c|c|c|}
\hline Studies & Randomisation described & Allocation concealment* & Outcome assessment blinded & $\begin{array}{l}\text { Withdrawals/loss to follow-up } \\
\qquad(\%)^{*}\end{array}$ & Funding \\
\hline Barnett et al $2008^{27}$ & Yes & Yes & Yes & 14 & Industry \\
\hline Davidson et al $2005^{22}$ & No & Yes & Yes & 18 & Industry \\
\hline Farmer et al $2007^{26}$ & Yes & Yes & Yes & 12 & Non-industry \\
\hline Guerci et al $2003^{23}$ & No & Yes & Yes & 31 & Industry \\
\hline O'Kane et al $2008^{25}$ & Yes & Yes & Yes & 2 & Non-industry \\
\hline Schwedes et al $2002^{24}$ & No & Yes & Yes & 11 & Industry \\
\hline
\end{tabular}

${ }^{*}$ Clarified with lead author when unclear in published reports. 
Table 3 | Characteristics of people at baseline randomised to either self monitoring or no self monitoring of blood glucose level. Values are numbers (percentages) unless stated otherwise

\section{Category}

Self monitoring group $(n=1374)^{\star}$ Control group $(n=1178)^{\star}$ Total $(n=2552)$

Age group (years):

\begin{tabular}{|c|c|c|c|}
\hline$\leq 45.0$ & $104(7.7)$ & $85(7.4)$ & $189(7.6)$ \\
\hline $45.9-55.0$ & $365(27.2)$ & $277(24.1)$ & $642(25.8)$ \\
\hline $55.9-65.0$ & $413(30.8)$ & $386(33.6)$ & $799(32.1)$ \\
\hline $64.9-75.0$ & $388(28.9)$ & $338(29.4)$ & $726(29.1)$ \\
\hline$>75.9$ & $72(5.4)$ & $63(5.5)$ & $135(5.4)$ \\
\hline Men & $735(53.8)$ & $640(54.5)$ & $1375(54.1)$ \\
\hline Women & $631(46.2)$ & $534(45.5)$ & $1165(45.9)$ \\
\hline \multicolumn{4}{|l|}{ Treatment: } \\
\hline Diet only & $209(20.2)$ & $167(19.9)$ & $376(20.1)$ \\
\hline Monotherapy & $405(39.2)$ & $321(38.2)$ & $726(38.7)$ \\
\hline Combined therapy & $420(40.6)$ & $353(42.0)$ & $773(41.2)$ \\
\hline \multicolumn{4}{|l|}{ Ethnicity: } \\
\hline White & $408(86.6)$ & $265(82.6)$ & $673(85.0)$ \\
\hline Mixed & $3(0.6)$ & $2(0.6)$ & $5(0.6)$ \\
\hline Asian & $9(1.9)$ & $6(1.9)$ & $15(1.9)$ \\
\hline Black & $17(3.6)$ & $12(3.7)$ & $29(3.7)$ \\
\hline Chinese or other & $2(0.4)$ & $1(0.3)$ & $3(0.4)$ \\
\hline Hispanic & $32(6.8)$ & $35(10.9)$ & $67(8.5)$ \\
\hline New to testing & $308(77.6)$ & $192(80.0)$ & $500(78.5)$ \\
\hline Tested before & $89(22.4)$ & $48(20.0)$ & $137(21.5)$ \\
\hline \multicolumn{4}{|l|}{ Duration of diabetes (months): } \\
\hline$\leq 24$ & $551(40.7)$ & $449(38.6)$ & $1000(39.7)$ \\
\hline$>25$ & $803(59.3)$ & $714(61.4)$ & $1517(60.3)$ \\
\hline Mean (SD) weight (kg) & 86.3 (17.3); n=1366 & $84.6(17.0) ; n=1172$ & $85.5(17.2)$ \\
\hline Mean (SD) body mass index & $31.1(6.1) ; \mathrm{n}=1356$ & $30.6(5.7) ; n=1166$ & $30.9(5.9)$ \\
\hline \multicolumn{4}{|l|}{ Mean (SD) $\mathrm{HbA}_{1 \mathrm{c}}$ level (mmol/mol) (\%): } \\
\hline$\leq 64.0(\leq 8.0)$ & $670(50.8)$ & $570(50.0)$ & $1240(50.4)$ \\
\hline $64.9-75.0(8.5-9.0)$ & $303(23.0)$ & $284(24.8)$ & $587(23.8)$ \\
\hline$>75.5-86.0(9.5-10.0)$ & $226(17.2)$ & $164(14.4)$ & $390(15.9)$ \\
\hline$\geq 86.5(>10.0)$ & $118(9.0)$ & $124(10.9)$ & $242(9.9)$ \\
\hline Mean (SD) blood pressure $(\mathrm{mm} \mathrm{Hg})$ : & $n=1144$ & $\mathrm{n}=960$ & \\
\hline Systolic & $138.6(16.1)$ & $139.3(15.7)$ & $138.9(15.9)$ \\
\hline Diastolic & $80.8(8.9)$ & $81.3(8.6)$ & $81(8.8)$ \\
\hline Mean (SD) total cholesterol level & $5.18(1.2) ; \mathrm{n}=629$ & $5.33(1.4) ; \mathrm{n}=477$ & $5.24(1.3)$ \\
\hline Ever smoker & $105(13.0)$ & $89(14.1)$ & $194(13.5)$ \\
\hline Mean (SD) fasting plasma glucose level & $7.26(4.5) ; n=599$ & $7.36(4.2) ; n=588$ & $7.31(4.4)$ \\
\hline
\end{tabular}


Table 4| Changes in HbA1c level and other outcomes from baseline between participants allocated to either self monitoring or no self monitoring of blood glucose levels

\begin{tabular}{|c|c|c|c|c|c|c|c|}
\hline Outcomes & No of trials & $\begin{array}{c}\text { No in self } \\
\text { monitoring } \\
\text { group }\end{array}$ & $\begin{array}{l}\text { No in control } \\
\text { group }\end{array}$ & $\begin{array}{l}\text { Unadjusted estimate* } \\
\qquad(95 \% \mathrm{Cl})\end{array}$ & $P$ value & $\begin{array}{c}\text { Adjusted estimate } † \\
(95 \% \mathrm{Cl})\end{array}$ & $\begin{array}{l}\text { Adjusted } P \\
\text { value }\end{array}$ \\
\hline \multicolumn{8}{|l|}{ Primary outcome } \\
\hline $\begin{array}{l}\mathrm{HbA}_{1 \mathrm{c}} \text { level }(\mathrm{mmol} / \mathrm{mol}) \\
\text { at } 6 \text { months }\end{array}$ & 6 & 1054 & 881 & $-2.5(-3.7$ to -1.4$)$ & $<0.001$ & $-2.7(-3.9$ to -1.6$)$ & $<0.001$ \\
\hline \multicolumn{8}{|l|}{ Secondary outcomes } \\
\hline \multicolumn{8}{|l|}{$\mathrm{HbA}_{1 \mathrm{c}}$ level $(\mathrm{mmol} / \mathrm{mol}):$} \\
\hline 3 months $\ddagger$ & 5 & 845 & 692 & $-1.9(-3.1$ to -0.7$)$ & 0.001 & $-2.0(-3.2$ to -0.9$)$ & 0.001 \\
\hline 12 months & 3 & 436 & 292 & $-2.4(-4.0$ to -0.8$)$ & 0.003 & $-2.5(-4.1$ to -0.9$)$ & 0.002 \\
\hline \multicolumn{8}{|l|}{$\begin{array}{l}\text { Blood pressure }(\mathrm{mm} \\
\mathrm{Hg}) \S:\end{array}$} \\
\hline Systolic & 3 & 876 & 732 & $-0.19(-1.39$ to 1.02$)$ & 0.76 & $-0.16(-1.37$ to 1.05$)$ & 0.79 \\
\hline Diastolic & 3 & 875 & 732 & $-0.05(-0.77$ to 0.68$)$ & 0.9 & $-0.15(-0.87$ to 0.58$)$ & 0.69 \\
\hline $\begin{array}{l}\text { Total cholesterol level } \\
(\mathrm{mmol} / \mathrm{l}) \boldsymbol{\Phi}\end{array}$ & 3 & 355 & 290 & $-0.05(-0.18$ to 0.08$)$ & 0.47 & $-0.06(-0.19$ to 0.07$)$ & 0.38 \\
\hline
\end{tabular}

*Effect of self monitoring allowing for baseline outcome measure, with trial and intervention coefficients as random effects.

†Effect of self monitoring after adjustment for age, sex, and duration of diabetes in unadjusted model.

‡Includes average of measurements at two and four months for two trials. ${ }^{22} 24$

§Outcomes are combination of measurements at six months ${ }^{2327}$ and 12 months. $^{26}$

ๆOutcome is combination of outcomes at six months ${ }^{24}{ }^{27}$ and 12 months. ${ }^{26}$ 


\section{Figures}

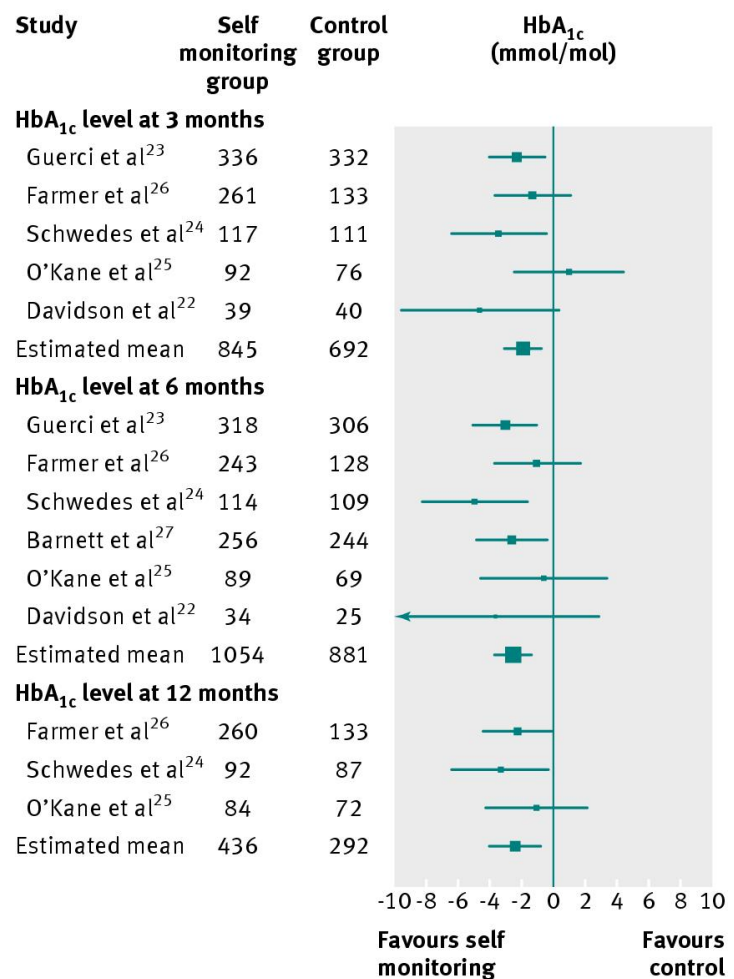

Fig 1 Changes in $\mathrm{HbA}_{1 \mathrm{c}}$ level between self monitoring and non-self monitoring of blood glucose groups from baseline to 3 , 6 , and 12 months

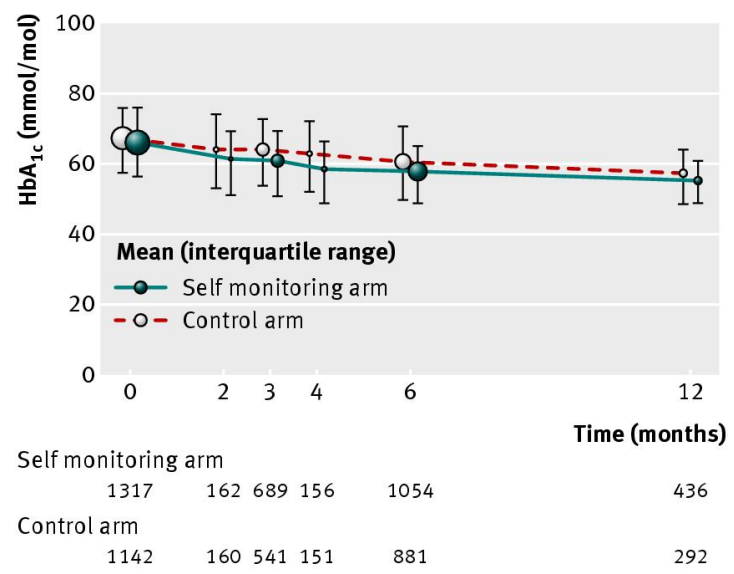

Fig 2 Changes in $\mathrm{HbA}_{1 \mathrm{c}}$ level between self monitoring and non-self monitoring of blood glucose groups from baseline overall and by trial 


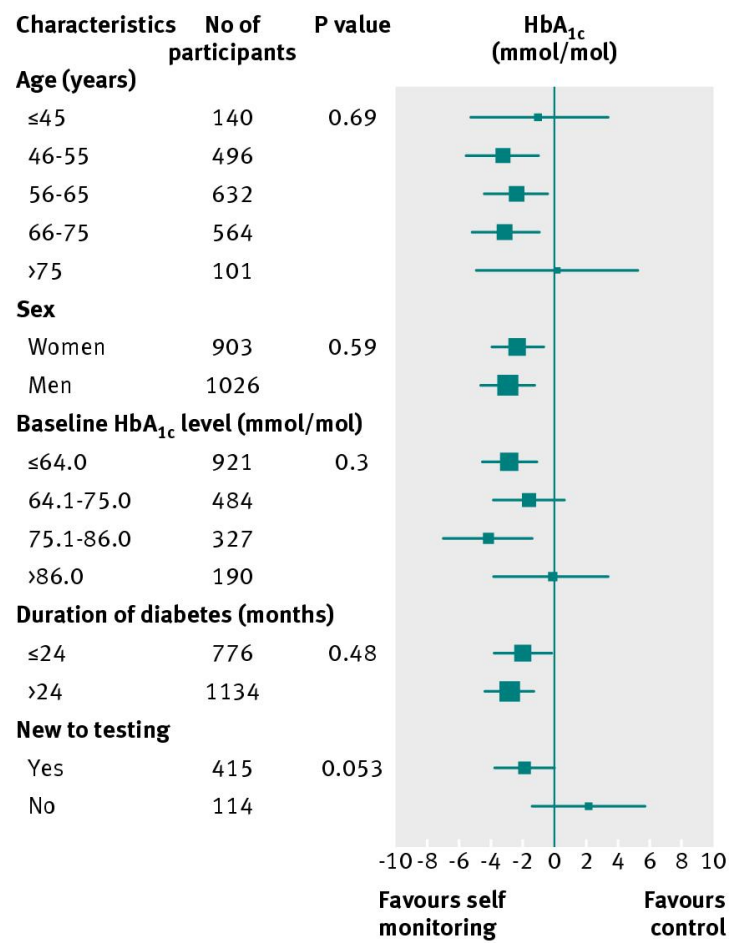

Fig 3 Change in $\mathrm{HbA}_{1 \mathrm{c}}$ level between self monitoring and non-self monitoring of blood glucose groups over six months by subgroup 